\title{
Coaches' perceptions of the potential use of performance analysis in
}

badminton

Andrew D. Butterworth, David J. Turner and James A. Johnstone

Sport, Health, Exercise Research Group, School of Life Sciences, University of Hertfordshire, United Kingdom.

\section{Abstract}

Despite performance analysis' proliferation as part of the coaching process, there remains a dearth of literature examining coaches' perceptions of its use. Equally, a distinct gap in literature exists examining the use of performance analysis in the context of badminton. This study aimed to address these issues through an exploration of badminton coaches' perceptions of the potential use of performance analysis in their coaching process. After analysing three badminton players' performance using objective video data, in depth individualised performance profiles were created. These were presented to seven badminton coaches, who were interviewed as to their perceptions of the utility of this analysis. Interview transcripts were analysed via content analysis, revealing that all bar one of the coaches directly praised the analysis undertaken and it's potential to aid coaching performance. Specifically, the majority of coaches praised the usefulness of the performance profiles as part of the wider coaching process, citing the ability to compare objective data to the performers own perceptions as particularly valuable. In this study the possible use of performance analysis in badminton was mostly well received by coaches, and this implicates it as a potentially key component in improving coach and athlete performance in an evolving coaching process.

Key words: Performance analysis, badminton, performance profiles, coaching process.

\section{Introduction}

Whilst the practical application of performance analysis (PA) is now widespread across many sporting contexts and skill levels, there is a dearth of literature examining coaches’ 
perceptions of the utilisation of PA. It is startling to note that despite its proliferation; currently there exists just one study (Groom \& Cushion, 2004) which explicitly investigates coaches' perceptions of the employment of PA as part of the coaching process. Furthermore, whilst badminton is widely recognised as the fastest moving racket sport, renowned for its high paced and energetic rallies, scholars have thus far invested minimal academic research into the sport, with only a few notable exceptions (Downey, 1973; Hong \& Tong, 2000; Lee, Xie \& Teh, 2005; Bedford, Barnett \& Ladds, 2010).

Previous research has examined the what of PA, while little attention seems to have been focused upon how to best implement PA within the coaching process (Groom, Cushion \& Nelson, 2011). Despite PA increasingly being considered as a key building block of the evolving coaching process, complimented by the provision of quality and finely tuned feedback directly related to objective data, it is still unclear what represents the optimal means by which to make the most of such data in coaching practice (Williams, 1999; Liebermann, Katz, Hughes, Bartlett, Clements \& Franks, 2002; Stratton, Reilly, Williams \& Richardson, 2004). Furthermore, it has been noted that the delivery of PA data to players and coaches alike is, more often than not, unstructured and predominantly reactive in nature rather than proactive (Groom, Cushion \& Nelson, 2011; Cushion \& Smith, 2006).

In general terms, the addition of PA to the coaching process has been reported to be potentially helpful in improving overall performance (Brown \& Hughes, 1995; Murray, Maylor \& Hughes, 1998). However, in relation to these findings it was suggested that a positive contribution of PA is contingent upon data being presented and communicated correctly. Moreover, no study has yet proved conclusively that the application of PA causes a significant improvement in performance. Hence, although previous research is inconclusive, those who have thus far examined the role PA plays in coaching have discovered that judgements may remain reserved on its overall use (Olsen \& Larsen, 1999).

PA practitioners make extensive use of video analysis and technology to critique and suggest improvements to sporting performance (Hughes, 2008). Many performance analysts working in competitive sport provide information on the opposition's strengths 
and weaknesses, in order to potentially seek advantage and annul them (Hughes \& Franks, 2005). This enables the prediction of certain tactical patterns that may be employed in a game situation, and informs how to possibly counteract these as part of the coaching process leading up to competition. Thus, it is vital that there is close liaison between coaching staff and athletes, to fully understand the exact needs of performers, and to tailor the application of PA to each individual or team (O’Donoghue, 2010).

Technology in PA continues to develop at an alarming rate, whilst the widespread use of PA in all sports to inform the coaching process is likely to become ever more prevalent (Franks, Hodges \& More, 2001). The role of the performance analyst has evolved over time, in line with changes from analogue, to digital technologies, still involving requisite expertise in coding and interpreting (Hughes \& Franks, 2004). It is also important to recognise that the coach must also establish a relationship of trust with the analyst, as well as be able to personally interpret the significance of the analysis before intertwining it within the coaching process (Hughes \& Franks, 2004).

Ironically, some coaches may feel that their job is under threat from new technology, and that their own experiences may be devalued. However, it has been advocated that both personal knowledge from the coach, and objective PA should be used together, in order to promote the greatest possible chance of improving performance and sporting outcomes (Bartlett, 2001; Liebermann, Katz, Hughes, Bartlett, McClements \& Franks, 2002). Nonetheless, it seems prudent that each individual coach should critically consider and settle upon their own preferred state of affairs with regards to the utilisation of PA, as suited to their sport, athletes, and personal interpretations of the coaching process (Robinson, 2010).

Conversely, Kerwin and Irwin (2008) sounded a warning to coaches using technology mindlessly within the coaching process, stating that a false impression can be created, in that images alone may be considered, to provide answers to technique and tactical issues. A common misconception is often made that if players observe what they are doing right or wrong in performance, this may help reinforce positive behaviours. However, it must be presented in the right way as part of a coaching process. Cushion and Smith (2006) reminded us that the coach is at the heart of the coaching process, and no matter what technical support is supplemented, the final decision on coaching matters ultimately lies 
with the coach who may or may not choose to embrace available technology, or use it appropriately. A holistic viewpoint, and a critical eye, taking into account and balancing the input of various disciplines (including PA), is required in order to maximise potential improvements in athletic performance.

Thus, the aim of this study is to investigate the personal perceptions that independent badminton coaches' have in regards to the inclusion of PA within the overall coaching process within their sport. Additionally, the paper seeks to develop and advance a framework of analysis for badminton performance specifically, as no such system is currently in widespread use.

\section{Methods}

Primarily this study investigates coaches' perceptions of PA in badminton. However, due to a lack of empirical badminton PA research, an analysis system was first created. Two main types of analysis were used, performance profiling, and court zone analysis.

Performance profiling invites a player to rank themselves on set key performance indicators (KPI), from 1 to 10; this data is then compared to objective data derived from videoed footage of the player. Performance profiling helps a coach to understand their athletes' subjective view of their performance and their relative strengths and weaknesses, and is well known as a powerful analytic tool focussed on the critical elements of performance (Butler, Smith \& Irwin, 1993; Doyle \& Parfitt, 1996; McGarry \& Franks, 1996; Hughes \& Franks, 2004). Using previous literature around the subject (Lee, Xie \& Teh, 2006), a court zone analysis system was further developed to examine the 6 zones in which points were won and lost during competitive badminton matches (Figure 2).

\subsection{Participants}

Having established the analysis system to be used, 3 recreational players (aged $32 \pm 6.5$ years) were recorded playing 6 competitive badminton matches to 21 points. Seven (one 
female, six male), qualified badminton coaches (aged $51 \pm 18.7$ years) were subsequently interviewed.

\subsection{Procedure}

After gaining institutional ethical approval, data collection was able to commence. All games were recorded live using a Sony HVR-A1E HD video camera, recorded using PA software (Sportscode elite, Sportstec, Warriewood, New South Wales, Australia) direct to a laptop (Apple Macbook A1181). Each match was post coded into seven main shot groupings (forehand clear, forehand smash, forehand drop, backhand clear, backhand drop, backhand smash and serve). Inter and intra user reliability was checked in relation to match coding, with 54 randomly selected instances coded by the lead researcher, and independently by another qualified badminton coach. Pearson's Moment Product Correlation reported reliability within the data collection. ( $r>0.96)$.

Having collected all raw data, each players data was entered into; a table for each game and overall (table 1), a performance profile (figure 1), and a court zone analysis for each game and overall (figure 2). The only previous study explicitly investigating coaches perceptions of PA (Groom \& Cushion, 2004), used 2 coaches for interview, a very small sample size. This number was not deemed sufficient for this study and so in line with guidelines surrounding theoretical saturation, 7 were used to increase the validity of the data (Strauss \& Corbin, 1998; Cohen, Manion \& Morrison, 2007).

Table 1. Raw data collection table.

\begin{tabular}{|l|l|l|l|}
\hline Shot & $\begin{array}{l}\text { Successful } \\
\text { Count }\end{array}$ & Percentage & Total Count \\
\hline FH Overhead & & & \\
\hline FH Drive & & & \\
\hline FH Net & & & \\
\hline BH Overhead & & & \\
\hline BH Drive & & & \\
\hline BH Net & & & \\
\hline Serve & & & \\
\hline Total & & & \\
\hline
\end{tabular}




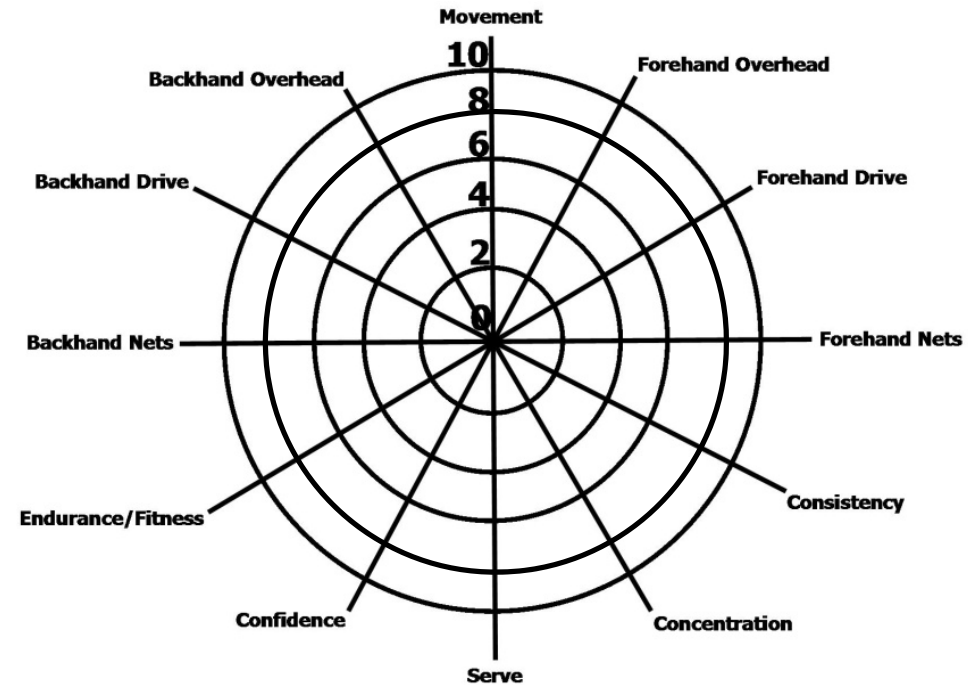

Figure 1. Blank performance profile.

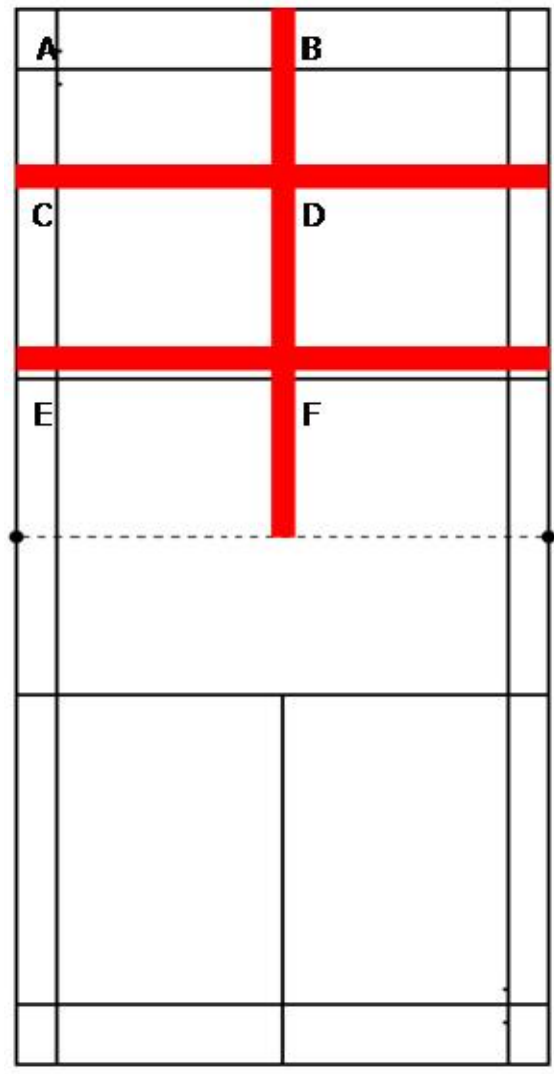

Figure 2. Court split diagram. 


\subsection{Interviews}

Performance profiles, court split's and statistics, alongside the original video data was presented to the 7 coaches in individual, semi structured interviews, with open ended questions, to identify meaningful themes and trends across the coaches interviewed. Following previous researchers (Groom \& Cushion, 2004) suggestions, five main areas were explored within the interview questions:

- General usefulness of the analysis

- Importance of player specificity

- Usefulness within the coaching process

- Usefulness within coaching practice

- Usefulness in other disciplines of coaching. 


\section{Results}

After undertaking a full content analysis, identifying 6 key higher order themes, the results of the interviews are herby presented in figure 3.

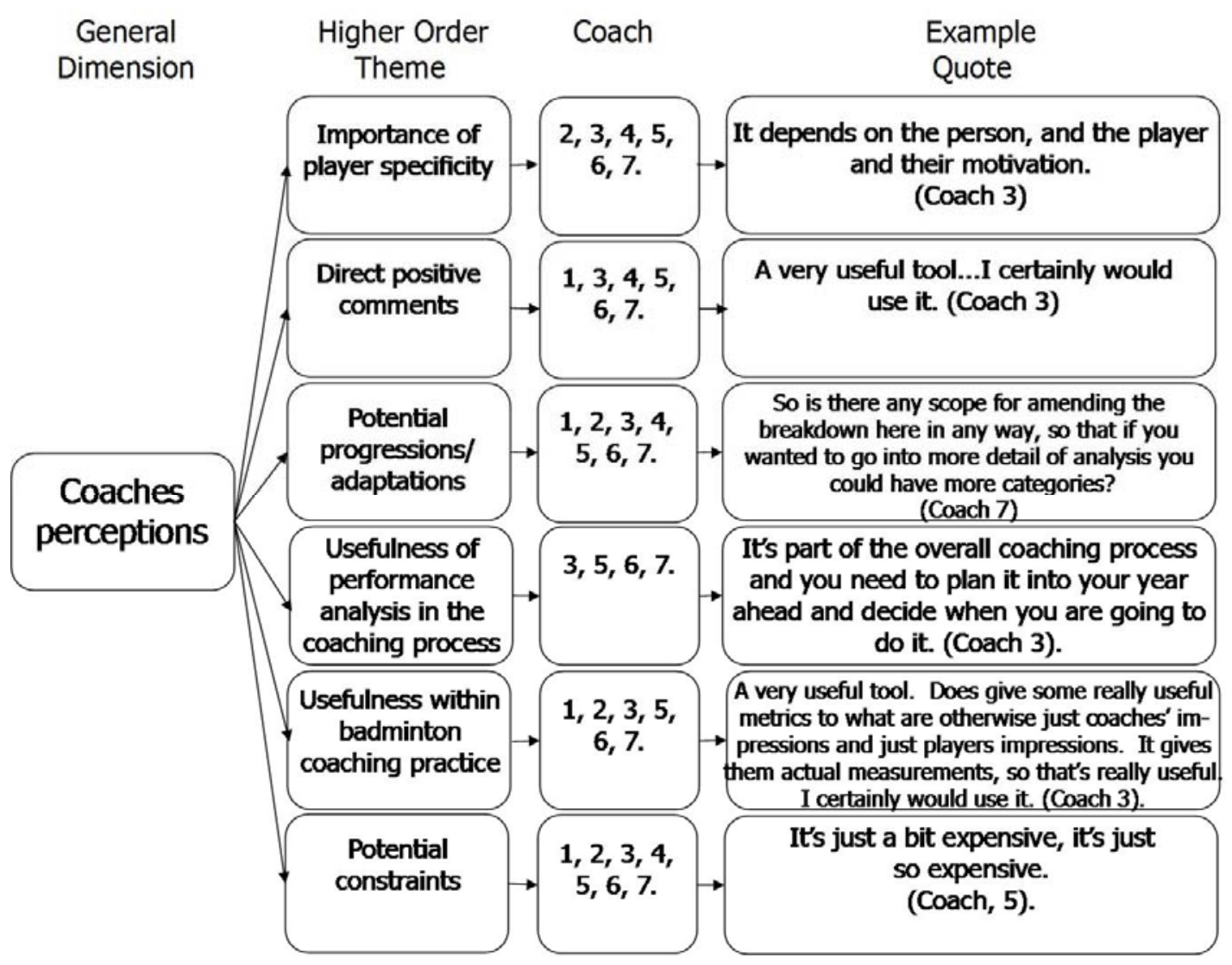

Figure 3. Results matrix.

\subsection{Player Specificity}

Four of the 6 sub themes identified are of particular interest and relevance in directly answering the research question. The first, and most heavily weighted, is the importance of player specificity. Six of the 7 coaches highlighted this as vitally important in deciding if to use the analysis or not:

It depends on the person and the player and their motivation, and how they take to numbers...It depends on the individual...It depends on their dedication and how they appreciate numbers. (Coach 3). 
...it's to do with the players attitude, I mean, you can get all sorts of ages from very young to much older who want to improve and listen and take it in and think about it, whereas you get others who just want to give it a bash...It's an attitude problem. And also as far as the younger players it’s also maturity, there are some who may be as young as the next player but concentrate and actually think older. (Coach 4).

...it would depend on the actual player because some don't take kindly to the analysis. It depends. (Coach 6).

Whilst the above three quotes illustrate the coaches' thinking of players in an individual basis, frequent reference was also made to the skill level or age of the performers in considering the use of the analysis:

The video, definitely elite players would learn a lot more from it than possibly beginners because they are going to see things in a way that the beginner won't because by the time you are one of the elite players, you are kind of self coaching...performance profile that's very good for the juniors, you can get very interactive with it and sort of see where they believe they think they are, where they think they can improve things like that. (Coach 5).

I think as they get older it could be used more and more... by the time they are 9 or 10 or 11 you can go into more detail. (Coach 3).

It is so easy to tell beginners you didn’t hit that back to him, you didn't hit it hard enough, it's so much easier to say that to a player, whereas with a better player it's a much more complex picture...with beginners it's getting the basics right...whereas elite players, they need the finer details which makes the difference between a very good player and a really very good player. (Coach 4).

\subsection{Analysis Methods}

Whilst the analysis was received well, many of the coaches highlighted the need to split the analysis more, making it more shot specific. Indeed many of the coaches directly asked if it was possible for the analysis to be split into the separate shots, rather than being generalised into categories: 
The thought that occurred to me when I looked at this categorization of the shot is that, if you take the forehand net, presumably that covers both net lifts and net kills, so that doesn't necessarily tell you a great deal because they are completely different shots...ok they are all vaguely similar, the clear, the drop and the smash, but they are different, so I think it would be useful if it were categorized in more detail. (Coach 2).

So is there any scope for amending the breakdown here in any way, so that if you wanted to go into more detail of analysis you could have more categories? (Coach 7).

If it was broken down more then we would be able to identify what was successful because it was a good shot, the right choice of shot or successfully executed the correct choice of shot. (Coach 4).

\subsection{Performance Profiles}

Six of the 7 coaches commended the performance profiles use within the coaching process, specifically highlighting the usefulness of visually seeing discrepancies between the players' perceived performance and actual performance:

With the beginners I would definitely use the performance profile. So very good I think, again lots of interaction and they get to know where they believe they are, and what you believe they can do better, which they can decide for themselves if you are telling the truth or not but again they can at least have a target to grow towards. (Coach 5).

I think the fact that your making the players think about what they are doing is the key thing. You make them think - Ok how are you performing in that area? Then breaking it down to the essentials and then the feed-back with how you are actually doing. (Coach 7).

This looks very powerful, particularly this difference between how the player sees themselves and how they are actually performing...encourage the player that he can play a bit better than he thinks he can. You could build up a lot of selfconfidence; which I try to do anyway with the coaching I do (Coach 1). 


\subsection{Subjective vs. Objective}

It is widely recognised that PA objectively measures actual data, and so through its use, no bias or coach opinions may distort feedback to athletes. Several of the coaches highlighted this in interview:

That would be a great way to show a player what they are doing because while you are coaching you can get into arguments with players saying that they think they are doing it a certain way and they are actually not and if you've got something to show them they can’t argue against it. (Coach 5).

We could do half a dozen repeat shots and they can see how consistent they are being, get into a game, and say 'ah, use that shot again'. So that they know on a more subjective level, how they are doing and what they are doing. (Coach 1).

A very useful tool. Does give some really useful metrics to what are otherwise just coaches' impressions and just players impressions. It gives them actual measurements, so that's really useful. (Coach 3).

\subsection{Summary}

The general perception of the analysis presented to the coaches is especially positive. All bar one of the coaches interviewed explicitly complimented the analysis, whilst also relating it to their own current coaching environment and explaining how they would implement it in their practices. It was also explained that there were benefits for both coach and player alike:

\section{Player Benefits}

- Improved confidence

- Visually able to see what coach is communicating

- Objectivity provided to coaching points

\section{Coach Benefits}

- Enhance own coaching practices

- Provides fine details to aid coaching of high performance players 


\subsection{Discussion}

This research represents a rare attempt at documenting coaches' perceptions of the use of PA in the coaching process. Furthermore, the embryonic analysis system created as part of this study for the sport of badminton potentially provides a basis for other analysis systems to be developed.

Having critically considered the outcomes of the investigation, it is evident that the overwhelming reaction to the analysis was positive. Six of the seven coaches directly praised the analysis, with very few negative comments offered (and even these largely including suggestions as to possible improvements). The four sub themes previously highlighted, provide critical insight as to the nature and detail of coaches' perceptions of the analysis.

\subsection{Individuality}

Whilst it was directly highlighted by all of the coaches that the analysis is potentially very helpful, it was noted that they would only consider using it with certain individuals. Specifically, the coaches stated that whether they would employ the analysis was dependant on a players' current competence level in badminton specific skills. It was also suggested that the maturation level and learning style of the individual player would affect the coaches' decision whether or not to use the analysis. This observation, made by all coaches interviewed, is in accordance with previous literature (Williams, 1999). The majority of the coaches thus informed the researcher that they would progressively employ PA as the players grew in both age, and maturity:

...definitely elite players would learn a lot more from it than possibly beginners, because they are going to see things in a way that the beginner won't... (Coach 5).

I think as they get older it could be used more and more... by the time they are 9 or 10 or 11 you can go into more detail (Coach 3).

Williams (1999) provided 10 key components to providing feedback, three of which were directly concerned with the skill level of the performer, which further emphasises the requirement for careful consideration in deciding which form of analysis is to be used, as 
was also outlined by the coaches interviewed in this study. For instance, It was recommended by those interviewed, that feedback should be provided from the captured video footage, potentially also utilising it to construct and evaluate a before and after video, or a comparison to an ideal technical model such as a professional player:

And using what you have shown here, the angles and things like that, you could coach them if they haven't got the right sort of angles that they are using... and go back and re video on court and see how near you get to it and play them back again. (Coach 3).

Do you do any superimpositions...like get a Gail Emms (ex England badminton player)... how you are performing in relation to her? (Coach 1 ).

Thus, this study has allowed this area of literature to be extended, further evidencing the need to take into account the performer on an individual basis whilst also considering the type of performance analysis feedback to be utilised. Furthermore, it was highlighted by the coaches that the employment of this analysis could also help them to develop personally as a coach, and to hone their coaching abilities:

Well, it's certainly useful to quantify my own feelings...this just gives you much more metric...I can see there are two main purposes there...one for me and one for them. (Coach 3).

I am interested to note how many of these things I might have noticed myself. (Coach 2).

This notion is in tandem with Groom and Cushion (2004) who found that youth football coaches experienced personal development through using video analysis with their players, enhancing both their own development as a coach, through adding to their portfolio of skills, whilst also helping them to plan specific coaching sessions resulting directly from the analysis undertaken. Therefore, the objective analysis performed in this study has again concurred with previous literature; providing further depth and justification as to the inclusion of PA as part of the coaching process. 


\subsection{Objectivity}

Previous research (Franks, Hodges \& More, 2001; Hughes, 2008) revealed that PA provides largely objective data, seemingly free from bias and opinion. The results of this study indicate that the analysis presented to the coaches for this study also was perceived to minimise bias. One coach specifically described an example of where this objective data could be used in coaching practice, in order to help dissuade a player that he was performing a skill correctly:

That would be a great way to show a player what they are doing, because while you are coaching you can get into arguments with players saying that they think they are doing it a certain way, and they are actually not, and if you've got something to show them they can’t argue against it. (Coach 5).

Hence, another reason is presented for the attractiveness of the analysis performed; not only does it aid coaches in improving their coaching through the utilisation of more objective data, it also aids players in understanding and apprehending the differences between perceived performance and actual performance, through utilising performance profiles.

\subsection{Perceived utility of performance profiles}

Many explicit positive themes were directly alluded to by the coaches in relation to the performance profiles created. It was highlighted by the coaches that attention to the difference between how the player perceives their own performance and how they are actually performing is of particular value. This view is in line with previous research around performance profiles (Butler, 1996), which revealed that this process is able to help performers in understanding how to achieve higher levels of performance in their chosen sport. This may be achieved via the facilitation of dialogue between coaches and players regarding how to go about improving discrepancies made apparent via the profile, as per another suggestion by some coaches interviewed within this study. Two coaches ( $1 \& 5$ ), expressly indicated that they would sit down with their performers once the profiles had been completed, and identify areas in which more coaching is needed, so that specific coaching sessions could be implemented. These suggestions are in harmony with previous findings which illustrate that performance profiles are useful in tailoring 
coaching, and identifying interventions to specifically meet with the athlete's needs, in order to develop their game on an individualised level (Butler, 1999; Peter Harrison Centre for Disability Sport, 2008).

Coaches additionally observed that profiles could be positively used in helping to develop player confidence. If a player were to rank himself on a skill at the lower end of the scale, but the objective data shows that he performs the skill at a much better level, then it was explained by the coaches that encouragement may be provided that he can actually play the shot better than he perceives is so himself.

You could build up a lot of self-confidence (Coach 1).

...some people have a completely off point of view of what is going on and they rate themselves really badly, when they need a bit of a pick-up you can fill in reality. (Coach 7).

In relating back how these results correspond to previous research, the building of confidence through video analysis is in accordance with the findings of the one previous study upon coaches' perceptions of video analysis (Groom and Cushion, 2004). In that investigation coaches were directly asked to state areas in which video analysis sessions had helped the players, and increasing confidence was featured as one of these.

\subsection{Coaches Experience}

The participants' age range (21-73) provided conflicting views, perhaps to be expected, resulting in some divergence of opinion. The younger coaches $(5,6,7)$ cited many more positives than the older coaches $(1,2,3,4)$. The only coach who failed to directly praise the analysis in any way (2) was in fact the oldest coach of all those interviewed. This difference in opinion between younger and older coaches might be speculated to be due to the coaching philosophy each group might adhere to. A coaching philosophy is considered to be a set of holistic values and principles that a coach uses to guide their coaching related decision making (Cassidy, Jones \& Potrac, 2004; Hardman \& Jones, 2008). With PA having not been prevalently used in racket sports prior to the introduction of a system by Downey (1973), it may be the case that older coaches continue to apply their personal philosophies with little regard or consideration to utilising new 
technologies that were not in use when they commenced badminton coaching. Certainly in the context of badminton, PA remains severely limited, and a lack of exposure and familiarity might result in older coaches being less inclined to praise its use here. It may also be the case that the younger coaches, who might have observed, and be more aware of, the benefits of analysis in other sports, are more inclined to praise the system developed for badminton in this study. Of course, it could simply be that younger coaches are more au fait with new technology, and find it less of a perceived potential threat to their coaching status.

\subsection{Limitations and Delimitations}

In examining the success of this study, three weaknesses become apparent in potentially having limited the overall results. Primarily, in the analysis itself, perhaps the main limitation of the study is the lack of specificity in categorising the shots, with all seven coaches commenting upon this. It may thus have slightly skewed the resulting perceptions. However, as has previously been explained, the analysis is in accordance with other research (O’Donoghue, 2010), which recommended that future performance analysis studies should be generic and experimental in approach. Nonetheless, the seven coaches interviewed all commented upon this, adding suggested examples of how to categorise the shots. However, as no previous literature exists in relation to coaches' perceptions of PA in badminton, this study drew on the authors' and a second level two qualified badminton coach's experiences in deriving an initial shot groupings to be analysed. Since Manrique and González-Badillo (2003) claimed that it is not yet known which are the most important shots in performance level badminton, there seems some justification for the generic analysis conceived of and performed in this study.

Within the actual PA that was undertaken, reliability was an issue, as is common in all PA work and studies (O’Donoghue, 2007; O’Donoghue, 2010). Despite an external coach checking the coding performed by the authors, the possibility remained that mistakes could have been made, and not rectified before the statistics and performance profiles were created. When human operators code live footage time pressures may contribute to such mistakes. Within the zonal analysis, some subjectivity remained; for example, if the player hit a shot, or lost a point on the dividing line between two zones, the choice was made as to which zone it was recorded as. 
Thirdly, time constraints may have limited the full perceptions the coaches being interviewed provided, due to the coaches' other pressing commitments time for interview was limited. Bryman (2008) explained that time is often a key issue that can affect qualitative research interviews.

\subsection{Implications of study}

This study has partially addressed two distinct gaps in scholarly literature, concerning both badminton and PA. In so doing, it has been discovered that level two and above badminton coaches, operating at a sub-elite level, are mostly very positive about the inclusion of PA as part of the overall coaching process. The coaches interviewed also alluded to the positive effects that performance profiling specifically could bring to assisting badminton coaching. Whilst other sources have previously examined performance profiles (Butler, 1996; Butler, Smith \& Irwin, 1993; Doyle \& Parfitt, 1996), this is the first to examine their use in badminton. It is therefore pleasing for the authors that this study has gleaned largely positive reactions from the coaches involved, and may open up opportunities for further research and applied practice to be conducted in this area.

With no unequivocal justification of the use of PA in the coaching process, it is also suggested by the authors, that an updated coaching process model should be created to reflect recent technological advances and the consequent proliferation of diverse PA interventions that are and may be incorporated to potentially help to improve athlete performance. Coaches may need such broad guidance as to the range of possible applications, in order to fully appreciate the potential use of PA in particular sporting contexts.

\subsection{Suggestions for future research}

Whilst this study did exceed the number of coaches involved in Groom and Cushion's (2004) investigation from 2 to 7, it is by gauging the perceptions of more coaches that a wider perception of the use of PA in badminton could be sought. Having established that coaches are mostly positive about PA, another study could alternatively examine players' perceptions of the analysis. The study could analyse a number of individual players, and 
record differences in their performance over a number of weeks before interviewing the players, in employing a similar method.

It is also important to try to anticipate where technology will take PA in years to come, so that imagined futures might be provoked by researchers in relation to these potential further studies. Hughes and Franks (2004) stated that PA will continue to evolve and develop, in line with global technological advances. Indeed, with the introduction of tablet computers and touch screen devices, PA is becoming ever more portable and accessible on the fields of play. For instance, anecdotal evidence notes several professional football clubs now utilise portable computers to inform half time team talks, and tactical changes to the game as it is actually in play. Advances also continue to be made in the software itself, with more additional complex features now on the market. Thus, another future study could utilise tablet devices, in an attempt to provide instantaneous feedback to athletes and coaches, and to assess the perceived impact of this type of intervention.

\subsection{Conclusions}

The embryonic analysis system presented for this study may provide a basis to inform and develop PA in badminton further. Further investigation and expansion of the analysis system will allow for a more detailed analysis of playing patterns. It has been noted that whilst PA can provide objective feedback, it must be presented in the right way, as part of the overall coaching process, a model that may now require updating to bring it in line with technological advances.

In conclusion, this unique paper has created a basic badminton PA system to be developed, building upon limited previous research in the area. It is apparent that PA as part of the coaching process in badminton is well received, with many benefits for both coach and player alike.

\section{References}

Bartlett, R. (2001). Performance analysis: can bringing together biomechanics and notational analysis benefit coaches? International Journal of Performance Analysis in Sport, 1(1), 122-126. 
Bedford, A., Barnett, T. \& Ladds, M. (2010). Risk taking in badminton to optimize inthe-run performance. Proceedings of the 10th Australasian Conference on Mathematics \& Computers in Sport, 2010. (pp. 20-26). Darwin, NT.

Butler, R. (1996). Performance profiling. Leeds: The National Coaching Foundation.

Butler, R. (1999). Performance profiling. Leeds: The National Coaching Foundation.

Butler, R. J., Smith, M. \& Irwin, I. (1993). The performance profile in practice. Journal of Applied Sport Psychology, 5(1), 48-63.

Brown, D. \& Hughes, M. (1995). The effectiveness of quantitative and qualitative feedback on performance in squash. In T. Reilly, M. Hughes \& A. Lees (Eds.), Science and Racquet Sports. (pp. 232-237). Leeds: E. \& F.N. Spon.

Bryman, A. (2008). Social research methods. Oxford: Oxford University Press.

Cassidy, T., Jones, R. \& Potrac, P. (2004). Understanding sports coaching: the social, cultural and pedagogical foundations of coaching practice. Oxon:

Routledge.

Cohen, L., Manion, L. \& Morrison, K. (2007). Research methods in education. Oxon: Routledge.

Cushion, C. J. \& Smith, M. (2006). An investigation of the in-game behaviours of professional top level youth soccer coaches. Journal of Sports Sciences, 24(4), 355-366.

Downey, J. C. (1973). The singles game. London: E. P. Publications.

Doyle, J. \& Parfitt, G. (1996). Performance profiling and predictive validity. Journal of Applied Sport Psychology, 8(2), 160-170.

Franks, I. M., Hodges, N \& More, K. (2001). Coaching behaviour. International Journal of Performance Analysis in Sport, 1(1), 27-36. 
Groom, R. \& Cushion, C. J. (2004). Coaches perceptions of the use of video analysis: A case study. Insight, The F.A. Coaches Association Journal, 7, 5658.

Groom, R., Cushion, C. J. \& Nelson, L. (2011). The delivery of video-based performance analysis by England youth soccer coaches: towards a grounded theory. Journal of Applied Sport Psychology, 23(1), 16-32.

Hardman, A. \& Jones, C. (2008). Philosophy for coaches. In R. Jones, M. Hughes \& K. Kingston. (Eds.), An introduction to sports coaching from science and theory to practice. (pp. 64-72). Oxon: Routledge.

Hong, Y. \& Tong, Y.M. (2000). The playing pattern of the world's top single badminton players in competition. Journal of Human Movement Studies, 38, 185-200.

Hughes, M. D. (2008). Notational analysis for coaches. In R. Jones, M. Hughes, K. Kingston, (Eds.), An introduction to sports coaching: from science and theory to practice. (pp 101-114). London: Routledge.

Hughes, M. D. \& Franks, I. M. (2004). Notational analysis - a review of the literature. In M. Hughes \& I. M. Franks (Eds.), Notational analysis of sport: systems for better coaching and performance in sport. (pp. 59-104). London: Routledge.

Hughes, M. D. \& Franks, I. M. (2005). Possession length and goal-scoring in soccer. Journal of Sport Sciences, 23(5), 509-514.

Kerwin, D.G. and Irwin, G. (2008). Biomechanics and coaching. In R. Jones, M. Hughes, K. Kingston, (Eds.), An introduction to sports coaching: from science and theory to practice. (pp 87-100). London: Routledge.

Lee, K. T., Xie, W. \& Teh, K. C. (2005). Notational analysis of international badminton competitions. In Q. Wang. (Ed.). Proceedings of XXIII International Symposium on Biomechanics in Sports, pp. 387-390. Beijing, China. 
Liebermann, D. G., Katz, L., Hughes, M. D., Bartlett, R. M., McClements, J. \& Franks, I. M. (2002). Advances in the application of information technology to sport performance. Journal of Sports Sciences, 20(10), 755-769.

Manrique, D. C. \& González-Badillo, J. J. (2003). Analysis of the characteristics of competitive badminton. British Journal of Sports Medicine, 37, 62-66.

McGarry, T. \& Franks, I. M. (1996). Development, application, and limitation of a stochastic Markov model in explaining championship squash performance. Research Quarterly for Exercise and Sport, 67(4), 406-415.

Murray, S., Maylor, D. \& Hughes, M. (1997). The effect of computerised analysis as feedback on the performance of elite squash players. In A. Lees, M. Hughes, T. Reilly \& I. Maynard (Eds.). Science and Racket Sports II. (pp. 235-240). London: E. \& F. N. Spon.

O’Donoghue, P. (2007). Reliability issues in performance analysis. International Journal of Performance Analysis in Sport, 7(1), 35-48.

O’Donoghue. (2010). Research methods for sports performance analysis. Oxon: Routledge.

Olsen, E., Larsen, O. (1997). Use of match analysis by coaches. In T. Reilly, J. Bangsbo \& M. Hughes (Eds.). Science and football III (pp. 209-220). London: E. \& F.N. Spon.

Peter Harrison Centre for Disability Sport (2008). Performance profiling and its use in talent identification in Paralympic sports, 2, Retrieved November 23, 2011 from

http://www.peterharrisoncentre.org.uk/Research\%20Digest/Performance\%20 Profiling_Helen\%20Alfano.pdf

Robinson, P. (2010). Foundations of sports coaching. Oxon: Routledge.

Stratton, G., Reilly, T., Williams, A. M. \& Richardson, D. (2004) Youth soccer; From science to performance. London: Routledge. 
Strauss, A. \& Corbin, J. (1998). Basics of qualitative research: Techniques and procedures for developing grounded theory. London: Sage Publications Ltd. Williams, A.M. (1999). Providing feedback during skill learning: The ten commandments. Insight, The F.A. Coaches Association Journal, 3(3), 12-13.

\section{Correspondence}

Sport, Health, Exercise Research Group, School of Life Sciences, University of Hertfordshire, United Kingdom.

Email: a.butterworth2@herts.ac.uk 